\title{
Poly(vinyl chloride) and Poly(E-caprolactone) Blends for Medical Use
}

\author{
Mihai Rusu* AND Mihaela Ursu \\ Faculty of Industrial Chemistry \\ Department of Macromolecules \\ "Gh. Asachi" Technical University of Iasi \\ Bd. Mangeron 71A, 700050 - Iasi, Romania \\ DANIELA RUSU \\ Faculty of Medical Bioengineering \\ Department of Biomaterials \\ "Gr. T. Popa" University of Medicine and Pharmacy of Iasi \\ 700115 - Iasi, Romania
}

\begin{abstract}
This study examines the possibility of replacing partially or totally the di(2-ethylhexyl) phthalate (DEHP - low molecular plasticizer) from the poly(vinyl chloride) (PVC) compositions intended for medical devices, with poly( $\varepsilon$-caprolactone) ( $\mathrm{PCL}$ - biodegradable, biocompatible, and macromolecular plasticizer). Nine different plasticized PVC (PVC-P) compositions are analyzed from the viewpoint of thermal and mechanical properties, plasticizer loss, and extraction behavior in different medical media. After comparing the experimental results with the data from the literature, corresponding to traditional PVC-P, it can be concluded that the PCL and even PCL-DEHP mixture behave as better plasticizers for PVC, providing a lower extraction risk and similar or even improved thermal and mechanical properties.
\end{abstract}

KEY WORDS: poly(vinyl chloride) (PVC), plasticizers, poly ( $\varepsilon$-caprolactone) (PCL), plasticizer loss, extraction behavior in different medical media.

*Author to whom correspondence should be addressed. E-mail: mrusu@ch.tuiasi.ro

Journal of Thermoplastic COMPOSITE MAterials, Vol. 19-March 2006 


\section{INTRODUCTION}

D Oly(VINYl Chloride) (PVC) is a linear, thermoplastic, substantially amorphous polymer, with huge commercial interest due to the accessibility to basic raw materials and its properties [1].

When plasticized, PVC presents some interesting properties (flexibility, strength, transparency, kink resistance, scratch resistance, wide range of gas permeability, biocompatibility, ease of bonding with common solvents or adhesives, and stability from gamma, ethylene oxide or E-beam sterilization) that allowed it to be widely accepted for use in flexible medical products (infusion, dialysis, blood, urine, and secretion bags; blood tubing for hemodialysis, endotracheal tubes, intravenous solution dispersion set, catheters, contact lenses, gloves as well as for drug product storage and packaging). In addition, many other PVC medical devices have passed critical toxicological, biological, and physiological tests [2-5].

From the large number of plasticizers that can be used for plasticizing PVC, the class of phthalic acid esters, mainly di(2-ethylhexyl) phthalate (DEHP), are widely used for medical devices as a result of their cost convenience and adaptability [4,5]. Nevertheless, since these plasticizers are low-molecular substances and not covalently bonded to the polymer, they can leach from the matrix. The migration degree of the plasticizer from the plasticized PVC (PVC-P) medical devices into the fluids which come in contact with them depends on several factors, such as nature and amount of the plasticizer, type of the medium being stored in or moving through the medical devices (e.g., DEHP is leached by polysorbate 80 , polyoxyethylated castor oil, cyclosporine, miconazole, chlordiazepoxide hydrochloride, and etopoxide), $\mathrm{pH}$, surfactants, temperature and storage time of the device while in contact with medical solutions, manufacturing process etc. [6-9].

Several studies have reported that using DEHP as a plasticizer for PVC provides: (1) wide range of flexibility for PVC, (2) an increase of survival time of platelets, (3) low acute toxicity with intravenous (IV) or oral (po) administration, and (4) no specific toxicity in the human body [10]. Nevertheless, the last two characteristics are controversial issues. While some studies agree with these conclusions [3,10], some others notice the existence of DEHP or metabolites in the blood, urine, or tissues of patients following treatment with PVC medical devices, as a result of leaching processes, with possible serious medical complications for the patients (pulmonary insufficiency, pulmonary edema, testicular atrophy, liver cancer) [11-17].

Another risk of using PVC-P medical devices in an inappropriate way concerns the interactions between DEHP and some substances 
(drugs, salts, etc.) that are contained in the fluids coming in contact with PVC-P [6,18-21]. Migration of drug (e.g., insulin, vitamin E, acetate diazepam, and nitroglycerin) into plastics may lead to the drug concentration going below the therapeutic level [22].

At present, there are two important directions of research to solve the problem of human exposure to DEHP from PVC-P medical devices. The first direction concerns the replacement of PVC-P for medical use with polymers that are flexible without plasticizers (silicone rubber, polyurethane, etc.) [23].

The second alternative focuses on limiting the leaching of plasticizer from PVC-P medical devices by: (1) coating PVC-P bags with hydrophilic polymers, (2) cross-linking PVC-P with peroxides during processing, (3) grafting hydrophilic monomers, such as polyethylene glycol for improving blood compatibility, and (4) using polymeric plasticizers instead of low molecular ones [9]. The last method is based on the fact that polymeric plasticizers present low volatility, high resistance to extract, and low migration at high temperatures $[4,5]$.

Among the polymeric plasticizers that may be used for PVC intended for medical use, the aliphatic polyesters are of great interest $[4,5,24,25]$, especially poly( $\varepsilon$-caprolactone) (PCL) [26,27].

The possibility of using PCL as a plasticizer for PVC was reported in the 1960s $[28,29]$. The PVC-PCL blends are tougher, more extensible than those prepared with conventional plasticizers, with better drape, softness, and higher resistance to extraction by oil and water $[26,28,29]$.

The present study investigates the possibility of total/partial replacement of DEHP from PVC-P medical devices with PCL, to limit the human exposure to DEHP.

\section{EXPERIMENTAL}

\section{Materials}

The following materials were used to obtain the different PVC-P compositions:

- Poly(vinyl chloride) medical grade (Oltchim, Romania), Fikentcher's constant $\left(K_{\mathrm{w}}\right)=69.7$, absorption of plasticizer $=98 \%$;

- Poly( $\varepsilon$-caprolactone), CAPA 6500 (kindly provided by Solvay Caprolactones, United Kingdom), Numerical Molecular Weight $\left(M_{\mathrm{n}}\right)=50,000 \mathrm{~g} / \mathrm{mol}$ by GPC in tetrahydrofuran as mentioned by the producer; Melt Flow Index $\left(\mathrm{MFI}, 190^{\circ} \mathrm{C} ; 2.16 \mathrm{~kg}\right)=28 \mathrm{~g} / 10 \mathrm{~min}$;

- Di(2-ethylhexyl) phthalate; 99\%, Sigma-Aldrich, Germany; 
- Physiological serum (solution $0.9 \%$ sodium chloride in water), SICOMED S.A., Bucharest, Romania;

- Perfusions solution - Ringer type $(8.6 \mathrm{~g}$ potassium chloride, $0.3 \mathrm{~g}$ sodium chloride, and $0.5 \mathrm{~g}$ calcium chloride $/ 1000 \mathrm{~mL}$ ); SICOMED S.A., Bucharest, Romania;

- $10 \%$ glucoses perfusions solution, SICOMED S.A., Bucharest, Romania;

- Sanguine plasma, Blood Transfusion Center, Iasi, Romania.

\section{Sample Preparation}

Ten different blends were prepared as indicated in Table 1. The thermal stability of the blends was improved by adding dibutyltin dilaurate, 1.5 parts in weight (parts wt.) for 100 parts wt. of PVC-plasticizer (either PCL, DEHP, or PCL-DEHP mixture).

The blends were obtained using a laboratory twin roll mill heated from 140 to $170^{\circ} \mathrm{C}$, depending on the composition of the blends. The temperature of the cylinder was decreased by increasing the amount of liquid plasticizer. All blends were transformed into 1 and $6 \mathrm{~mm}$ plates by compression (preheating for $10 \mathrm{~min}$, pressure for $5 \mathrm{~min}$ at $145-175^{\circ} \mathrm{C}$, and $150 \mathrm{daN} / \mathrm{cm}^{2}$ cooling under pressure), from which samples were obtained for further characterization.

\section{Characterization Methods}

The blends were characterized from the viewpoint of thermal and mechanical properties, plasticizer loss, and extraction behavior in different media.

The thermal properties were measured by both the differential scanning calorimetry (DSC) and the dynamic mechanical analysis (DMA). The thermal characteristics (i.e., glass transition temperature $\left(T_{\mathrm{g}}\right)$, melting temperature $\left(T_{\mathrm{m}}\right)$, melting enthalpy $\left(\Delta H_{\mathrm{m}}\right)$, and heat capacity $\left.\left(\Delta C_{\mathrm{p}}\right)\right)$ were determined by the DSC using a Perkin-Elmer 7 series thermal analysis system, in the temperature range of $-100-100^{\circ} \mathrm{C}$. Samples were studied at four different heating/cooling rates: $9,16,25$, and $36 \mathrm{~K} / \mathrm{min}$. The $T_{\mathrm{g}}$ was determined as the midpoint of the heat-capacity increase of the second heating process and $T_{\mathrm{m}}$ as the endothermal peak in the DSC curve of the second heating process.

Dynamic mechanical analyses were carried out at a frequency of $1 \mathrm{~Hz}$, in a dual-cantilever bending mode, using a Dynamisch-mechanischer Analysator RSA II, Rheometrics Version 4.4 (Rheometrics Europe GmbH). The runs were conducted at $2^{\circ} \mathrm{C} / \mathrm{min}$ between -40 and $100^{\circ} \mathrm{C}$. The analyses were run 
Table 1. Compositions of PVC-P with PCL, DEHP, or PCL-DEHP mixtures and their thermal characteristics determined from DSC diagrams and by DMA.

\begin{tabular}{|c|c|c|c|c|c|c|c|c|c|c|}
\hline \multirow[b]{2}{*}{ Sample } & \multicolumn{3}{|c|}{ Blend composition } & \multirow{2}{*}{$\begin{array}{c}T_{\mathrm{g}} \\
\text { onset }^{\mathrm{a}}\left({ }^{\circ} \mathrm{C}\right)\end{array}$} & \multirow{2}{*}{$\begin{array}{l}T_{\mathrm{g}}^{\mathrm{a}} \\
\left({ }^{\circ} \mathrm{C}\right)\end{array}$} & \multirow{2}{*}{$\begin{array}{l}\Delta \mathbf{C}_{\mathrm{p}}{ }^{\mathrm{a}} \\
(\mathbf{J} / \mathbf{g})\end{array}$} & \multirow{2}{*}{$\begin{array}{c}T_{m} \\
\text { onset }^{\mathrm{a}}\left({ }^{\circ} \mathrm{C}\right)\end{array}$} & \multirow{2}{*}{$\begin{array}{l}T_{\mathrm{m}}{ }^{\mathrm{a}} \\
\left({ }^{\circ} \mathbf{C}\right)\end{array}$} & \multirow{2}{*}{$\begin{array}{l}\Delta H_{\mathrm{m}}{ }^{\mathrm{a}} \\
(\mathrm{J} / \mathrm{g})\end{array}$} & \multirow{2}{*}{$\begin{array}{c}T_{\mathrm{g}}^{\mathrm{b}} \\
\left({ }^{\circ} \mathrm{C}\right)\end{array}$} \\
\hline & PVC & PCL & DEHP & & & & & & & \\
\hline 1 & 100 & - & - & 76.7 & 86.7 & 0.962 & - & - & - & 89.4 \\
\hline 2 & 90 & 10 & - & 51.4 & 62.8 & 0.302 & - & - & - & 76.8 \\
\hline 3 & 80 & 20 & - & 28.9 & 42.9 & 0.341 & - & - & - & 52.2 \\
\hline 4 & 70 & 30 & - & -0.4 & 14.5 & 0.346 & - & - & - & 31.7 \\
\hline 5 & 60 & 40 & - & -7.3 & 1.8 & 0.295 & 50.9 & 60.8 & 5.176 & 18.2 \\
\hline 6 & 50 & 50 & - & -32.9 & -19.7 & 0.349 & 51.7 & 61.4 & 36.085 & 27.8 \\
\hline 7 & 60 & 30 & 10 & -19.6 & -4.9 & 0.271 & - & - & - & 10.7 \\
\hline 8 & 60 & 20 & 20 & -24.5 & -11.1 & 0.175 & - & - & - & 9.2 \\
\hline 9 & 60 & 10 & 30 & -34.8 & -24.1 & 0.221 & - & - & - & -2.02 \\
\hline 10 & 60 & - & 40 & -47.6 & -33.1 & 0.198 & - & - & - & -14.3 \\
\hline
\end{tabular}

aBy DSC diagrams upon heating from -100 to $100^{\circ} \mathrm{C}$ with a heating rate of $25^{\circ} \mathrm{C} / \mathrm{min}$.

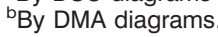


in tensile mode with samples of $\approx 40 \times 6 \times 1 \mathrm{~mm}^{3}$ dimensions. The autostrain was set to $3 \%$ and the dynamic force was $25 \%$. The curves displayed storage modulus $\left(E^{\prime}\right)$, loss modulus $\left(E^{\prime \prime}\right)$, and loss tangent $(\tan \delta)$ versus temperature. The $T_{\mathrm{g}}$ was taken to be the temperature for the maximum of the loss tangent curve.

The tensile behavior (stress-strain diagrams, tensile yield strength, tensile strength, elongation at break, and Young's modulus) of the samples was determined using a Zwick Z005 type tensile tester with a maximum speed of $3000 \mathrm{~mm} / \mathrm{min}$, and a power of maximum $5 \mathrm{kN}$, at $23^{\circ} \mathrm{C}$ with a relative humidity of $50 \%$ and a mobile clamp speed of $50 \mathrm{~mm} / \mathrm{min}$. All the samples were kept at the test temperature for $24 \mathrm{~h}$. Ten samples of each blend were tested and average values were reported.

The plasticizer loss was measured according to ASTM D1203-1992 (Test Method $\mathrm{A}, 70^{\circ} \mathrm{C}, 24 \mathrm{~h}$, using activated carbon method).

The resistance of PVC blends to extraction was analyzed according to ASTM F 619 1991, in the following media: physiological serum, Ringer solution, $10 \%$ glucose perfusions solution, and sanguine plasma, for $48 \mathrm{~h}$, at 37 and $90^{\circ} \mathrm{C}$, respectively on the disk samples of $1 \mathrm{~mm}$ thickness and $50 \mathrm{~mm}$ diameter.

\section{RESULTS AND DISCUSSION}

\section{Thermal Characteristics}

Differential scanning calorimetry is one of the most widely used techniques for determining the thermal characteristics $\left(T_{\mathrm{g}}, T_{\mathrm{m}}, \Delta C_{\mathrm{p}}\right.$, and $\left.\Delta H_{\mathrm{m}}\right)$ of polymers and polymer blends [30]. However, the studies have shown that the DSC values are influenced by several factors, the most important being the thermal history (heating or cooling) and the rate of heating/cooling [30]. To establish the influence of these two factors, Figure 1 and Table 2 present the DSC diagrams for PCL and the corresponding thermal characteristics.

During cooling cycles, after reaching the maximum temperature, the PCL sample was held at this temperature for $0.5 \mathrm{~min}$. During the heating cycles, the holding time was at the minimum temperature for $3 \mathrm{~min}$.

The analysis of the DSC diagrams (Figure 1) shows that the PCL exhibits both $T_{\mathrm{g}}$ and $T_{\mathrm{m}}$, a fact which confirms the semicrystalline structure of this polymer.

The data from Table 2 show that the $T_{\mathrm{g}}$ and $T_{\mathrm{m}}$ determined through the DSC diagrams depend on the thermal history and also on the heating/ cooling rate. It can be seen that the temperature that initiates the glass transition process ( $T_{\mathrm{g}}$ onset) and $T_{\mathrm{g}}$ value decreases with the increasing rate 


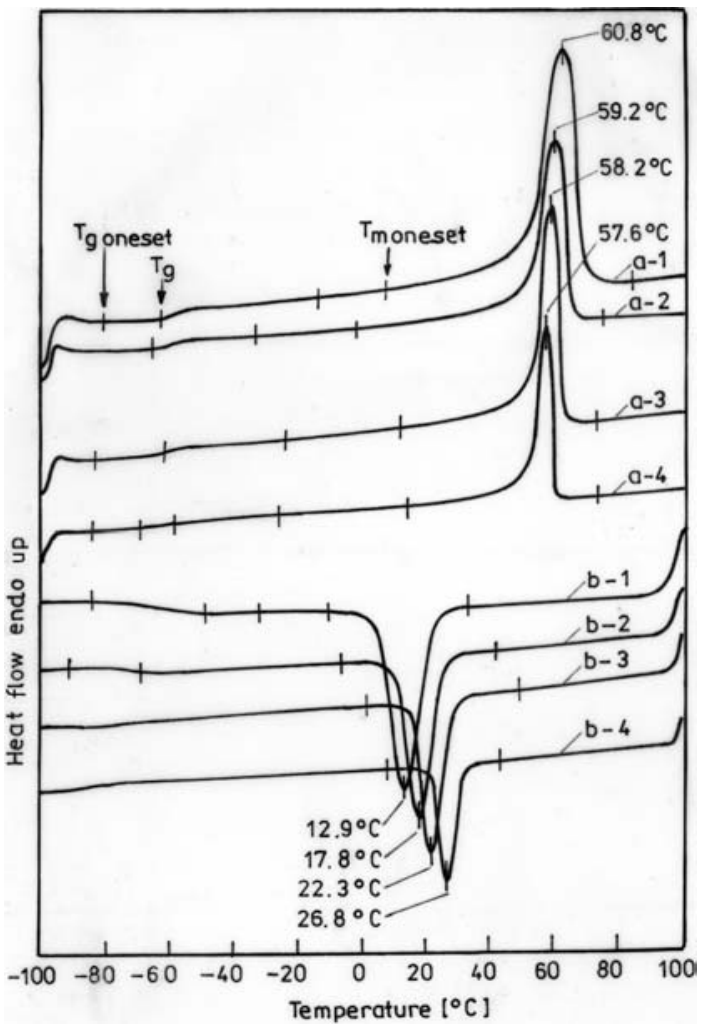

Figure 1. DSC diagrams for PCL: (a) heating from -100 to $100^{\circ} \mathrm{C}$ and (b) cooling from 100 to $-100^{\circ} \mathrm{C}$ : (1) $36^{\circ} \mathrm{C} / \mathrm{min}$; (2) $25^{\circ} \mathrm{C} / \mathrm{min}$; (3) $16^{\circ} \mathrm{C} / \mathrm{min}$; (4) $9^{\circ} \mathrm{C} / \mathrm{min}$.

Table 2. Thermal characteristics of PCL determined from DSC diagrams for different thermal histories.

\begin{tabular}{|c|c|c|c|c|c|c|c|c|}
\hline \multirow[b]{3}{*}{ Characteristics } & \multicolumn{8}{|c|}{ Heating/cooling rate } \\
\hline & \multicolumn{2}{|c|}{$36^{\circ} \mathrm{C} / \mathrm{min}$} & \multicolumn{2}{|c|}{$25^{\circ} \mathrm{C} / \mathrm{min}$} & \multicolumn{2}{|c|}{$16^{\circ} \mathrm{C} / \mathrm{min}$} & \multicolumn{2}{|c|}{$9 \mathrm{C} / \mathrm{min}$} \\
\hline & a & b & a & b & a & b & a & b \\
\hline$T_{\mathrm{g}}$ onset $\left({ }^{\circ} \mathrm{C}\right)$ & -63.5 & -49.7 & -65.5 & -61.7 & -68.4 & NO & -69.1 & NO \\
\hline$T_{\mathrm{g}}\left({ }^{\circ} \mathrm{C}\right)$ & -55.8 & -59.5 & -61.2 & -67.8 & -62.4 & NO & -68.6 & NO \\
\hline$T_{\mathrm{m}}$ onset $\left({ }^{\circ} \mathrm{C}\right)$ & 50.9 & 21.8 & 51.9 & 25.2 & 52.5 & 28.6 & 53.3 & 32.1 \\
\hline$T_{\mathrm{m}}\left({ }^{\circ} \mathrm{C}\right)$ & 60.8 & 12.9 & 59.6 & 17.8 & 58.2 & 22.4 & 57.5 & 26.8 \\
\hline$\Delta C_{\mathrm{p}}(\mathrm{J} / \mathrm{g})$ & 0.329 & 0.325 & 0.251 & 0.372 & 0.301 & NO & 0.549 & NO \\
\hline$\Delta H_{\mathrm{m}}(\mathrm{J} / \mathrm{g})$ & 62.805 & -56.632 & 65.311 & -57.878 & 62.091 & -58.430 & 60.764 & -59.126 \\
\hline
\end{tabular}

a Heating from -100 to $100^{\circ} \mathrm{C}$.

${ }^{\mathrm{b}}$ Cooling from 100 to $-100^{\circ} \mathrm{C}$.

$\mathrm{NO}$ - not observed. 
of the DSC experiment. The temperature that initiates the melting process ( $T_{\mathrm{m}}$ onset) increases and $T_{\mathrm{m}}$ decreases by lowering the rate of heating/ cooling. The characteristic temperatures ( $T_{\mathrm{g}}$ onset, $T_{\mathrm{g}}, T_{\mathrm{m}}$ onset, and $\left.T_{\mathrm{m}}\right)$ measured from the DSC diagrams upon heating exhibit higher values than the ones established during the cooling cycles.

The same influence of thermal history and heating/cooling rate from the DSC diagrams was also revealed for all the blends studied. To illustrate this observation, Table 3 presents the influence of the heating rate on $T_{\mathrm{g}}$.

Comparing the $T_{\mathrm{g}}$ and $T_{\mathrm{m}}$ values for PCL and PVC, as obtained from the DSC measurements in different conditions (PVC: $T_{\mathrm{g}}=86.7^{\circ} \mathrm{C}$; PCL: $\left.T_{\mathrm{g}}=-61.2^{\circ} \mathrm{C}, T_{\mathrm{m}}=59.6^{\circ} \mathrm{C}\right)$, with the values mentioned in literature (PVC: $T_{\mathrm{g}}=85^{\circ} \mathrm{C}$; PCL: $T_{\mathrm{g}}=-61^{\circ} \mathrm{C}, T_{\mathrm{m}}=60^{\circ} \mathrm{C}[1,27]$ ) it can be seen that the characteristics measured for a heating rate of $25^{\circ} \mathrm{C} / \mathrm{min}$ have similar values. Therefore, in this study we will consider only the values obtained in the second heating process, with a rate of $25^{\circ} \mathrm{C} / \mathrm{min}$ (Figure 2).

The DSC diagrams corresponding to the PVC-PCL blends with 40 and 50 parts wt. PCL respectively, exhibit both $T_{\mathrm{g}}$ and $T_{\mathrm{m}}$ (Figure 2 - diagrams 5 and 6), in contrast to those for PVC-PCL-DEHP blend (Figure 2 diagram 9) and PVC-DEHP blend (Figure 2 - diagram 10), that show only $T_{\mathrm{g}}$.

Thermal characteristics for all the analyzed blends are presented in Table 1. The results show that adding PCL in PVC compositions induces a decrease of $T_{\mathrm{g}}$ onset and $T_{\mathrm{g}}$ values (Samples 1-6), which is proof that the PCL acts as a macromolecular plasticizer for the PVC. In addition, it can be observed that the PVC blends with 40 and 50 parts wt. macromolecular plasticizer (Samples 5 and 6), and respectively, exhibit a melting point, quite close to the $T_{\mathrm{m}}$ value of PCL, indicating that these PVC-PCL blends contain distinct

Table 3. Influence of the heating rate on the $T_{g}$ of the PVC-P compositions.

\begin{tabular}{ccccc}
\hline & \multicolumn{3}{c}{$\boldsymbol{T}_{\mathbf{g}}\left({ }^{\circ} \mathbf{C}\right)$ - as determined at different heating rates } \\
\cline { 2 - 5 } Sample & $\mathbf{3 6} \mathbf{C} / \mathbf{m i n}$ & $\mathbf{2 5}^{\circ} \mathbf{C} / \mathbf{m i n}$ & $\mathbf{1 6} \mathbf{C} / \mathbf{m i n}$ & $\mathbf{9}^{\circ} \mathbf{C} / \mathbf{m i n}$ \\
\hline 1 & 90.5 & 86.7 & 84.1 & 82.9 \\
2 & 76.8 & 62.7 & 55.9 & 55.7 \\
3 & 48.7 & 42.9 & 39.8 & 35.0 \\
4 & 23.5 & 18.5 & 16.5 & 9.3 \\
5 & 4.1 & 1.8 & 1.3 & -2.9 \\
6 & - & -19.7 & - & - \\
7 & -5.2 & -4.5 & -6.7 & -11.7 \\
8 & -9.4 & -11.0 & -18.2 & -25.5 \\
9 & -22.8 & -24.1 & -25.6 & -29.5 \\
10 & -30.1 & -33.1 & -34.7 & -37.2 \\
\hline
\end{tabular}




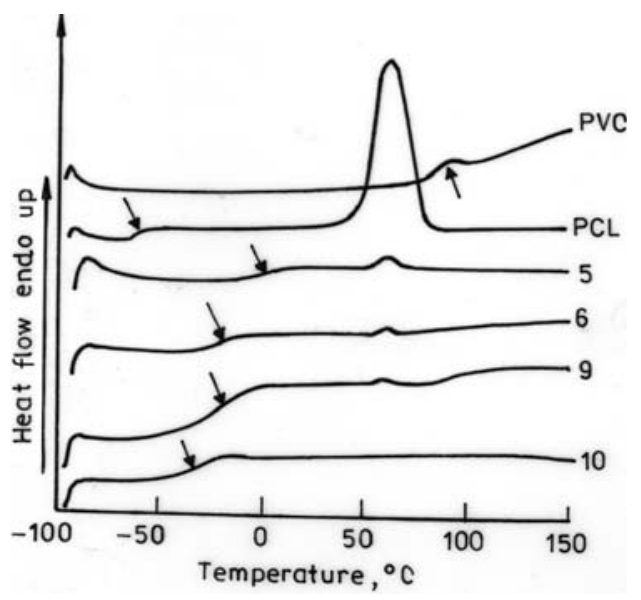

Figure 2. DSC diagrams for unplasticized PVC, $P C L$ and four different PVC-P compositions (Samples 5, 6, 9, and 10, respectively, from Table 1).

PCL crystalline regions. All these observations demonstrate that the PVC-PCL blends with $<40$ parts wt. PCL are homogenous, and after this value they became biphasic. The biphasic blends contain a PVC-PCL amorphous phase and a crystalline phase due exclusively to PCL. This biphasic morphology corresponding to PVC-PCL blends with $>40$ parts wt. PCL was also reported by other research studies [27].

The data from Table 1 show that adding PCL in PVC compositions induces an important decrease of $\Delta C_{\mathrm{p}}$ during the glass transition process, despite the fact that the amount of PCL has no significant effect on $\triangle C_{\mathrm{p}}$ values.

In the case of the PVC-PCL blends presenting a melting point (Samples 5 and 6$), \Delta H_{\mathrm{m}}$ increases with increasing amount of PCL; this corresponds to the increase of the crystalline fraction by adding a higher quantity of PCL in the PVC.

Gradually replacing the PCL from the PVC-PCL blends containing 40 parts wt. plasticizer (Samples 7-10) with DEHP results in a decrease of $T_{\mathrm{g}}$. Lowering $T_{\mathrm{g}}$ turns out to be more significant as the quantity of DEHP becomes larger. The DSC diagrams for the PVC-PCL-DEHP blends do not exhibit a melting point, a fact which indicates that these ternary systems present a single-phase structure.

In addition to the DSC, the DMA is also a very important method to measure $T_{\mathrm{g}}$ for polymers and polymer blends [30]. The DMA performed on the PVC-based blends evidences that adding PCL and/or DEHP in PVC induces a decrease of $T_{\mathrm{g}}$ values (Table 1, Figure 3 ). It can be noticed that 


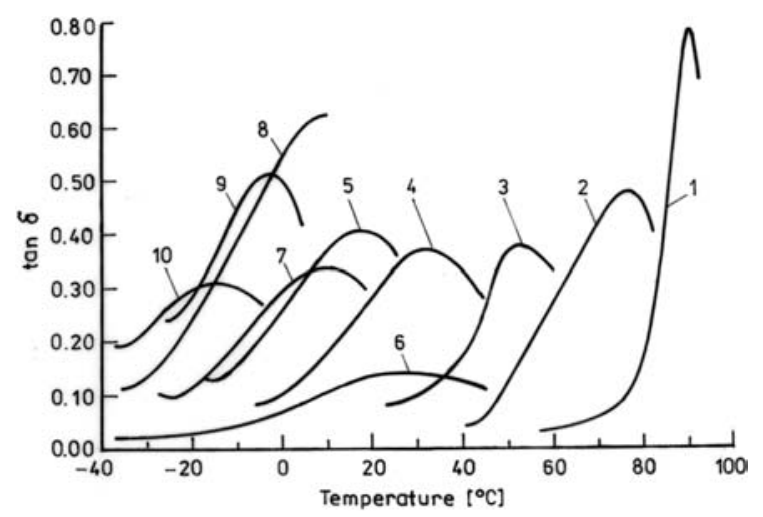

Figure 3. Plot of tan $\delta$ vs temperature for unplasticized PVC and our PVC-P compositions (the diagrams numbers correspond to the compositions numbers from Table 1).

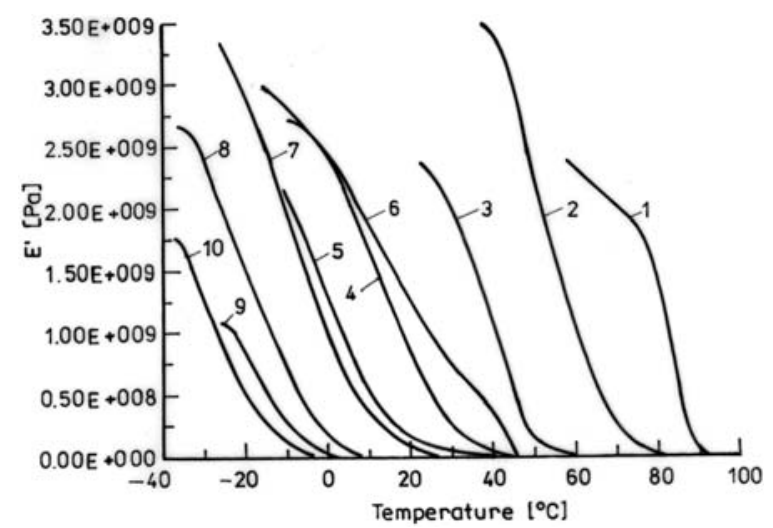

Figure 4. Plot of storage modulus vs temperature for unplasticized PVC and our PVC-P compositions (the diagrams numbers correspond to the compositions numbers from Table 1).

increasing the amount of plasticizer in PVC produces a continuous decrease of $T_{\mathrm{g}}$. An exception to this rule is given by the PVC-PCL blend with 50 parts wt. PCL, which was found to exhibit a higher value of $T_{\mathrm{g}}$ (Sample 6). Gradually replacing the PCL with DEHP from the PVC-PCL blends containing 40 parts wt. plasticizer results in a significant decrease of $T_{\mathrm{g}}$ (Samples 7-10).

Considering the DMA diagrams that show the storage modulus as a function of temperature (Figure 4) it can be seen that adding plasticizers (either PCL, DEHP, or PCL-DEHP mixture) in PVC dramatically changes their mechanical characteristics, by passing from brittle to tough plastics. It is important to observe that the curve for the PVC-PCL blend with 
40 parts wt. PCL presents the same shape as the one for the PVC-DEHP system with the same amount of plasticizer. Therefore, we can conclude that using PCL as a plasticizer has a similar effect as using DEHP as a plasticizer for PVC-P.

\section{Mechanical Characteristics}

Analyzing the stress-strain diagrams corresponding to the most significant PVC blends prepared, it can be observed that adding PCL in PVC in different quantities change the mechanical behavior of these blends (Figure 5).

Unplasticized PVC and PVC-PCL blend with 10 parts wt. PCL (diagrams 1 and 2 from Figure 5) behave like brittle plastics, in contrast with the blend containing 40 parts wt. PCL (diagram 5 from Figure 5), which is already a tough plastic that does not exhibit a yield point. While replacing the PCL with DEHP, the shape of stress-strain diagrams does not change. Moreover, the shape remains unchanged for all the PVC blends containing 40 parts wt. plasticizer, regardless of the plasticizer type (PCL, PCL-DEHP blend, or DEHP). This sustains the idea that the PCL acts as a plasticizer for PVC, confirming the conclusion given by analyzing the storage modulus-temperature diagrams (Figure 4).

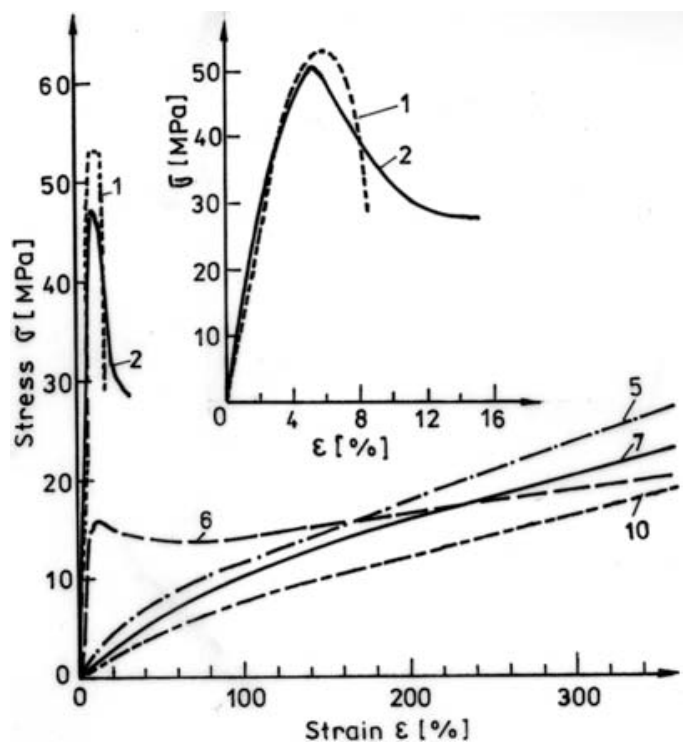

Figure 5. Stress-strain diagrams for PVC-PCL blends (the diagrams numbers correspond to the compositions numbers from Table 1). 
The mechanical characteristics studied (tensile yield strength, tensile strength, Young's modulus, and hardness) decrease while incorporating the PCL in PVC and this behavior is accentuated while increasing the amount of PCL (Table 4, Figure 6). An exception is the elongation at break that

Table 4. Mechanical properties of the PVC-P compositions.

\begin{tabular}{cccccccc}
\hline & $\begin{array}{c}\text { Tensile yield } \\
\text { strength }\end{array}$ & $\begin{array}{c}\text { Tensile } \\
\text { strength }\end{array}$ & $\begin{array}{c}\text { Young's } \\
\text { modulus }\end{array}$ & $\begin{array}{c}\text { Elongation } \\
\text { at break }\end{array}$ & \multicolumn{2}{c}{ Hardness } \\
\cline { 7 - 8 } & $\sigma_{\mathbf{Y}}(\mathbf{M P a})$ & $\sigma_{\mathbf{F}}(\mathbf{M P a})$ & $\boldsymbol{E}(\mathbf{M P a})$ & $\varepsilon_{\mathbf{F}}(\%)$ & Shore A & Shore D \\
\hline 1 & 53.04 & 29.32 & 2085 & 6 & 96.5 & 78 \\
2 & 52.50 & 27.09 & 1902 & 21 & 96 & 78 \\
3 & 39.39 & 26.29 & 1254 & 100 & 95 & 68 \\
4 & 28.62 & 24.10 & 126 & 209 & 94 & 46 \\
5 & 23.61 & 23.34 & 14 & 337 & 92.5 & 39 \\
6 & 20.51 & 20.21 & 291 & 355 & 91.5 & 34 \\
7 & 22.70 & 22.68 & 10 & 356 & 87 & 24 \\
8 & 19.45 & 19.44 & 3.2 & 407 & 75 & 20 \\
9 & 15.34 & 15.20 & 3.28 & 347 & 72.5 & 20 \\
10 & 16.90 & 16.78 & 4.15 & 364 & 75 & 21 \\
\hline
\end{tabular}

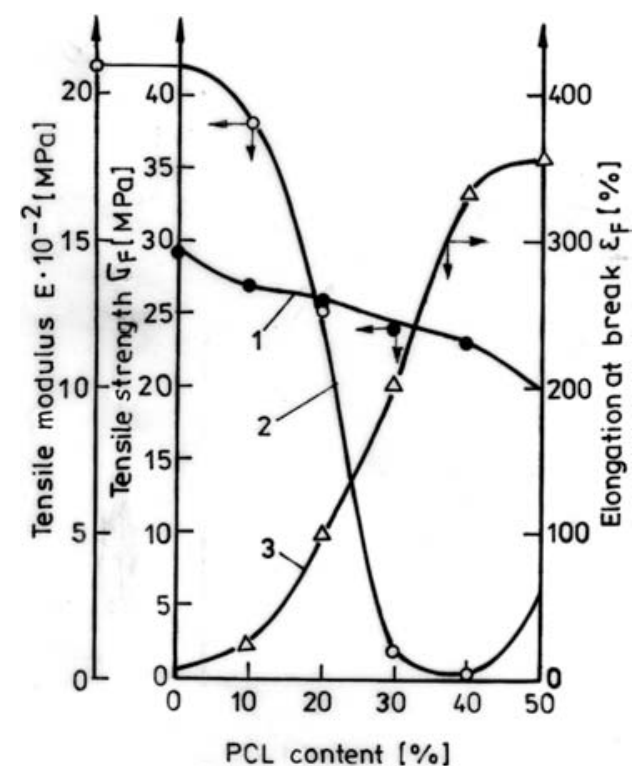

Figure 6. Influence of PCL fraction on tensile strength (1), Young's modulus (2), and elongation at break (3) of PVC-PCL blends. 
increases while increasing the proportion of PCL in the blends. Gradually replacing the PCL with DEHP results in a decrease of tensile yield strength and tensile strength, Young's modulus and hardness, but does not influence the elongation at break significantly.

Another exception to the general trend is the PVC-PCL blend with 50 parts wt. PCL, which presents a stress-strain diagram typical for the polymeric materials that exhibit a yield point (Figure 5). Moreover, Young's modulus of this blend is higher than that of the PVC-PCL blend with 40 parts wt. PCL (Table 4). This special behavior of the PVC-PCL blend with 50 parts wt. PCL is due to its biphasic structure (as revealed by thermal characterization), the amorphous part of PCL acting as a plasticizer for the PVC and the crystalline PCL behaving as a reinforcement agent [26], and that explains the higher value obtained for Young's modulus.

\section{Plasticizer Loss and Extraction Behavior in Different Media}

The results concerning the plasticizer loss from the PVC-P compositions and their resistance to extraction at different temperatures in different media are presented in Table 5. It can be seen that the loss of plasticizer from the PVC-PCL blends is negligible, even if a small increase of this value may be noticed while increasing the amount of PCL in the blends. By gradually replacing the macromolecular plasticizer (PCL) with the low-molecular one (DEHP) a major increase in plasticizer loss was detected (from $0.015 \%$ for PVC-P with 40 parts wt. PCL to $0.642 \%$ for the PVC-P plasticized with 30 parts wt. PCL and 10 parts wt. DEHP), the plasticizer loss increases while increasing the amount of DEHP in the blends.

The extraction experiments, irrespective of the extraction media or conditions used, indicate that adding PCL in PVC compositions induces a slight increase of the weight loss values, as compared with the unplasticized PVC (Table 5). By increasing the PCL fraction in the PVC-PCL blends, the weight loss values increased too, but still in a limited domain (maximum $0.51 \%$ for 50 parts wt. PCL blend). The highest values for weight losses at $37^{\circ} \mathrm{C}$ were found while using Ringer solution and sanguine plasma as the extraction media.

Comparing the weight loss for all the PVC compositions with 40 parts wt. plasticizer, it can be seen that greater the DEHP fraction in the blends, greater is the weight losses by extraction.

Increasing the temperature from 37 to $90^{\circ} \mathrm{C}$ determines a considerable increase of the weight loss values measured by the extraction. At $90^{\circ} \mathrm{C}$, the highest weight loss by extraction can be seen for the PVC compositions containing 40 parts wt. of either DEHP or PCL-DEHP mixture 25/75. 
Table 5. Plasticizer loss and extraction behavior in different media and at two temperatures of the PVC-P compositions.

\begin{tabular}{|c|c|c|c|c|c|c|c|c|}
\hline \multirow[b]{2}{*}{ Sample } & \multirow[b]{2}{*}{$\begin{array}{l}\text { Plasticizer } \\
\text { loss } \\
(\%)\end{array}$} & \multicolumn{7}{|c|}{ Weight loss by extraction (\%) } \\
\hline & & $\begin{array}{l}\text { Physiological } \\
\text { serum } \\
\left(37^{\circ} \mathrm{C}, 48 \mathrm{~h}\right)\end{array}$ & $\begin{array}{c}\text { Ringer } \\
\text { solution } \\
\left(37^{\circ} \mathrm{C}, 48 \mathrm{~h}\right)\end{array}$ & $\begin{array}{c}\text { Glucoses } \\
\text { solution } \\
(10 \%)\left(37^{\circ} \mathrm{C}, 48 \mathrm{~h}\right)\end{array}$ & $\begin{array}{l}\text { Sanguine } \\
\text { plasma } \\
\left(37^{\circ} \mathrm{C}, 48 \mathrm{~h}\right)\end{array}$ & $\begin{array}{l}\text { Physiological } \\
\text { serum } \\
\left(90^{\circ} \mathrm{C}, 48 \mathrm{~h}\right)\end{array}$ & $\begin{array}{c}\text { Ringer } \\
\text { solution } \\
\left(90^{\circ} \mathrm{C}, 48 \mathrm{~h}\right)\end{array}$ & $\begin{array}{c}\text { Glucoses } \\
\text { solution } \\
(10 \%)\left(90^{\circ} \mathrm{C}, 48 \mathrm{~h}\right)\end{array}$ \\
\hline 1 & 0.011 & 0.06 & 0.02 & 0.05 & 0.12 & 0.14 & 0.21 & 0.09 \\
\hline 2 & - & 0.10 & 0.12 & 0.10 & 0.22 & 1.25 & 0.60 & 0.11 \\
\hline 3 & - & 0.11 & 0.19 & 0.11 & 0.23 & 1.38 & 1.71 & 1.01 \\
\hline 5 & 0.015 & 0.15 & 0.46 & 0.25 & 0.29 & 4.5 & 4.25 & 3.92 \\
\hline 6 & 0.016 & 0.14 & 0.51 & 0.26 & 0.40 & 4.93 & 6.81 & 4.58 \\
\hline 7 & 0.642 & 0.30 & 0.53 & 0.27 & 0.48 & 8.98 & 17.81 & 7.51 \\
\hline 8 & 0.781 & 0.42 & 0.59 & 0.38 & 0.51 & 14.80 & 20.30 & 9.03 \\
\hline 9 & 0.853 & 0.80 & 0.62 & 0.51 & 0.62 & 27.47 & 21.49 & 12.31 \\
\hline 10 & 0.901 & 0.81 & 0.65 & 0.57 & 1.04 & 27.86 & 26.35 & 27.57 \\
\hline
\end{tabular}


To demonstrate the advantages of using PCL or PCL-DEHP mixture as plasticizers for PVC medical devices, the results are compared with the data from the literature, which refer to conventional PVC-P medical devices (Table 6).

First comparison concerns the mechanical properties of different PVC-P compositions, such as the tensile strength and Young's modulus. The use of PCL for plasticizing PVC provides an improvement of these two mechanical characteristics, in comparison with the PVC-P containing classical lowmolecular plasticizers, such as DEHP, trioctyl trimellitate (TOTM), dioctyl adipate (DOA). Gradually replacing the PCL with DEHP decreases these mechanical characteristics, up to values comparable to those for the PVC-DEHP compositions. On the contrary, the nature of plasticizer does not influence the elongation at break significantly, the data for PVC-P with PCL, DEHP, or PCL-DEHP mixtures are close to the data mentioned in the literature [31].

Shore A hardness of the PVC-PCL blends is higher compared to those of the traditional PVC-P compositions, using low molecular plasticizers. While replacing partially PCL with DEHP, the hardness values become comparable with those of the PVC plasticized with low molecular plasticizers.

Another important comparison element is the plasticizer loss and the weight loss by extraction in different media and once again it may be observed that the PVC plasticized only with PCL presents a better resistance to extraction and loses a much lower amount of plasticizer, compared to the data presented in the literature for PVC plasticized with DEHP, TOTM, or DOA. Even partially replacing DEHP from the traditional PVC-P with PCL induces a decrease of plasticizer loss by migration or extraction, the mechanical properties are only slightly affected. Consequently, the disadvantages induced by the use of DEHP as a plasticizer for PVC medical devices can be totally or at least partially eliminated.

\section{CONCLUSIONS}

The aim of this study was to investigate the possibility of partial/total replacement of DEHP (low molecular plasticizer) from PVC medical devices, with PCL (biodegradable, biocompatible, and macromolecular plasticizer). Thermal and mechanical properties, the plasticizer loss, and extraction behavior in different medical media, of different PVC compositions plasticized with PCL and PCL-DEHP mixture were analyzed and compared with the data from the literature. The results suggest that PCL and even the PCL-DEHP mixture behave as better plasticizers for PVC, providing a lower extraction risk and similar or even improved thermal and mechanical properties. 
Table 6. Comparison between the experimental data and the data from the literature for different PVC-P compositions.

\begin{tabular}{|c|c|c|c|c|c|c|c|}
\hline \multirow[b]{3}{*}{ Characteristics } & \multicolumn{7}{|c|}{ Plasticizer type } \\
\hline & \multicolumn{2}{|c|}{ DEHP } & \multirow[b]{2}{*}{$\begin{array}{c}\text { TOTM } \\
\text { [31] }\end{array}$} & \multirow[b]{2}{*}{$\begin{array}{l}\text { DOA } \\
{[31]}\end{array}$} & \multirow[b]{2}{*}{ PCL } & \multicolumn{2}{|c|}{ PCL-DEHP blend } \\
\hline & $\begin{array}{l}\text { Literature } \\
\text { data [31] }\end{array}$ & $\begin{array}{l}\text { Experimental } \\
\text { data }\end{array}$ & & & & $50 / 50$ & $25 / 75$ \\
\hline Plasticizer contain (phr) & 54 & $66^{a}$ & 56 & 42 & $66^{a}$ & $66^{a}$ & $66^{a}$ \\
\hline Young's modulus (MPa) & 3.28 & 10.3 & 10.5 & 10.3 & 14.0 & 10.0 & 4.15 \\
\hline Elongation at break (\%) & 330 & 364 & 370 & 380 & 337 & 407 & 347 \\
\hline Shore A hardness & 80 & 75 & 84 & 81 & 94 & 87 & 75 \\
\hline $\begin{array}{l}\text { Plasticizer loss (\%) ASTM D1203 } \\
\quad\left(24 \mathrm{~h}, 90^{\circ} \mathrm{C}\right)\end{array}$ & 1.7 & 0.9 & 0.4 & - & 0.015 & 0.781 & 0.853 \\
\hline \multicolumn{8}{|l|}{ Weight loss by extraction (\%) } \\
\hline Water $\left(24 \mathrm{~h}, 50^{\circ} \mathrm{C}\right)$ & 0.2 & - & 0.13 & 0.4 & - & - & - \\
\hline $\begin{array}{l}\text { Soap water }(1 \%) \\
\left(24 \mathrm{~h}, 50^{\circ} \mathrm{C}\right)\end{array}$ & 5.3 & - & 0.12 & 16.5 & - & - & - \\
\hline
\end{tabular}

TOTM - trioctyl trimellitate; DAO - dioctyl adipate.

${ }^{a} 60$ parts in wt. PVC, 40 parts in wt. plasticizer, 1.5 parts in wt. heat stabilizer. 


\section{REFERENCES}

1. Andrady, A.L. (1998). Poly(vinyl chloride), In: Mark, J.E. (ed.), Polymer Data Handbook, p. 928, Oxford University Press, Oxford, UK.

2. Hansen, O.G. (September 1995). PVC in the Health Care Sector, Medical Device Technology, Octo Media Ltd., London, UK, 20-29.

3. Nair, C.S.B. (March 1996). The Use of PVC for Critical Medical Applications, Medical Device \& Diagnostic Industry, A Technical-Economic News Magazine for Medical Plastics and Pharmaceutical Industry, Los Angeles, USA.

4. Bruder, A., Linder, S., Mügge, J., Saffert, R. and Spinder, E. (1999). PVC - der Werkstoff für Medizinprodukte, Products (PVC - Material Designed for Medical Device, Products), Swiss Plastics, 4: 15.

5. Bruder, A., Linder, S., Mügge, J., Saffert, R. and Spinder, E. (1999). PVC - der Werkstoff für Medizinprodukte (PVC - Material Designed for Medical Device), Swiss Chem., 5: 34.

6. Rubin, R.J. and Ness, P.M. (1989). What Price Progress? An Upgrade on Vinyl Plastic Bags, Transfusion, 29(4): 358.

7. Mazur, H.I., Stennett, D.J. and Egging, P.K. (1989). Extraction of DEHP from Total Nutrient Solution - Containing Polyvinyl Chloride Bags, J. Parenter Enteral Nutr., 13(1): 59-62.

8. Rubin, R.J. and Schiffer, C.A. (1976). Fate in Humans of Plasticiser DEHP Arising from Transfusion Platelets Stored in Vinyl Plastic Bags, Transfusion, 16(4): 330-335.

9. Lakshimi, S. and Jayakrishnan, A. (1998). Migration Resistant, Blood - Compatible Plasticized PVC for Medical and Related Applications, Artificial Organ, 22(3): 222.

10. Pearson, S.D. and Trissel, L.A. (1981). Leaching of DEHP from PVC Containers by Selected Drugs and Formulated Components, Am. J. Hosp. Pharm., 38(9): 1308.

11. Doelman, C.J.A., Borm, B.J.A. and Blast, A. (1990). Plasticizers and Bronchial Hyperreactivity, Lancet, 335: 725.

12. Doelman, C.J.A., Borm, B.J.A. and Blast, A. (1990). Plasticizers another Burden for Asthmatics, Agents Actions Suppl., 31: 81.

13. Barry, Y.A., Labow, R.S., Rock, G. and Kean, W.J. (1988). Cardiotoxic Effects of the Plasticizer Metabolite, Mono(2-ethylhexyl) Phthalate (MEHP), on Human Myocardium, Blood, 72(4): 1438.

14. Dickerson, R.N. (1997). Di(2-ethylhexyl) Phthalate Plasticizer for Intravenous Bags and Tubing: A Toxicological Quandary, Nutrition, 13: 1010.

15. Smith, M.D., Grant, M.H., Blass, C.R., Courtney, J.M. and Barbenel, J.C. (1995). Poly (vinyl chloride) Formulations: Acute Toxicity to Culture Human Cell Lines, J. Biomater. Sci. Polym., 7(3): 466.

16. Doull, J., Cattley, R., Elcombe, C., Lake, G.B., Swenberg, J., Wilkinson, C., Williams, G. and Van Gemer, M. (1999). A Cancer Risk Assessment of Di(2-ethylhexyl) Phthalate: Application of the New US EPA Risk Assessment Guidelines, Regul. Toxical. Pharmacol., 29(3): 327.

17. Dostal, L.A., Chapin, R.E., Stefanski, S.A., Harris, M.W. and Schwetz, B.A. (1988). Testicular Toxicity and Reduced Sertoli Cell Number in Neonatal Rats by Di(2-ethylhexyl) Phthalate and Recovery of Fertility as Adults, Toxical. Appl. Pharmacol., 95(1): 104.

18. Nassberger, L., Arbin, A. and Ostrelins, J. (1987). Exposure of Patients to Phthalates from Polyvinylchloride Tubes and Bags during Dialysis, Nephron, 45(4): 286.

19. Faouzi, M.A., Dine, T., Gressier, R., Kambia, K., Luyckx, M., Paguiez, D., Brunet, C., Cazin, M., Belabed, A. and Cazin, J.C. (1999). Exposure of Hemodialysis Patients to Di(2-ethylhexyl) Phthalate, Int. J. Pharma, 180(1): 113. 
20. Jager, R.J. and Rubin, R.J. (1972). Migration of Phthalate Ester Plasticizer from Polyvinylchloride Blood Bags into Stored Human Blood and its Localization in Human Tissues, N. Engl. J. Med., 287(22): 1114.

21. Karle, V.A., Short, B.L., Martin, G.R., Bulas, D.I., Getson, P.R., Luban, N.L., O'Brain, A.M. and Rubin, R.J. (1977). Extracorporal Membrane Oxygenation Exposes Infants to Plasticizer Di(2-ethylhexyl) Phthalate, Crit. Care Med., 25(4): 696.

22. Manojkumar, V., Padmakumaran Nair, K.G., Santhosh, A., Deepadevi, K.D., Arun, P., Lackshini, L.P. and Kurup, P.A. (1998). Decrease in the Concentration of Vitamin E in Blood and Tissues caused by Di(2-ethylhexyl) Phthalate, a Commonly used Plasticizer in Blood Storage Bags and Medical Tubing, Vox Sang, 75(2): 139.

23. Ko, J.H. and Odegaard, L. (1997). Chlorine-Free Blends for Flexible Medical Tubing, Medical Plastics as Biomaterials.

24. Rusu, M. and Rusu, D.L. (2003). Polyvinyl Chloride based-blends, In: Vasile, C. and Kulshreshtha, A.K. (eds), Handbook of Polymer Blends and Composites, Vol. 4A, pp. 73-120, RAPRA Technology, London, UK.

25. Hammer, C.F. (1978). Polymeric Plasticizers in Polymer Blends, In: Paul, D.R. and Newman, S. (eds), p. 219, Academic Press, San Diego.

26. Eastmond, G.C. (2000). Poly ( $\varepsilon$-caprolactone) Blends, Adv. Polym. Sci., 149: 59.

27. Iroh, I.O. (1999). Poly( $\varepsilon$-caprolactone), In: Mark, I.E. (ed.), Polymer Data Handbook, pp. 361-364, Oxford University Press, Oxford, UK.

28. Mullins, D.H. (1960). Plasticization of Vinyl Resins with Lactame Polyesters, Union Carbide Corp, Assignee, Canadian Patent, 742: 294.

29. Koleske, J.V. and Lundberg, R.D. (1969). J. Polym. Sci., A-2 7(3): 795.

30. Olabisi, O., Robeson, L.M. and Shaw, M.T. (1979). Polymer-polymer Miscibility, Academic Press, New York, NY, USA.

31. Adams, R.C. (2001). A Comparison of Plasticizers for Use in Flexible Vinyl Medical Products, Medical Device \& Diagnostic Industry, A Technical-Economic News Magazine for Medical Plastics and Pharmaceutical Industry, Los Angeles, USA. 